Article

\title{
Dynamic Performance of a New-Type PSC I-girder for Railway Bridge Application
}

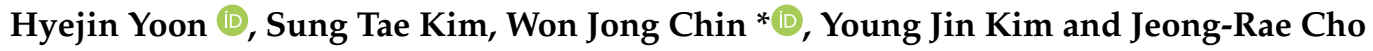

Korea Institute of Civil Engineering and Building Technology, 283 Goyangdae-ro, Ilsanseo-gu, Goyang-si, Gyeonggi-do 10223, Korea; hiyoon@kict.re.kr (H.Y.); esper009@kict.re.kr (S.T.K.); yjkim@kict.re.kr (Y.J.K.); chojr@kict.re.kr (J.-R.C.)

* Correspondence: wjchin@kict.re.kr; Tel.: +82-31-910-0662

Received: 9 November 2020; Accepted: 2 December 2020; Published: 5 December 2020

\begin{abstract}
This study intends to verify analytically and experimentally the performance of a new type of prestressed concrete (PSC) I-girder for its application as railway bridge. Since the girder-type railway bridge develops relatively low torsional rigidity, there is risk for the dynamic responses to amplify due to the superposition of the torsional mode and flexural mode. The superposition of the torsional and flexural modes as well as the dynamic stability of the railway bridge were examined through dynamic analysis. Three-dimensional modelling was built to be suitable for carrying out moving load analysis. Four different span lengths of 30, 35, 40 and $45 \mathrm{~m}$ adopted considering the most applied span length currently and future lengthening of the span length. Moreover, a full-scale girder specimen with span length of $35 \mathrm{~m}$ was fabricated and subjected to dynamic loading. The measured dynamic responses were then compared to the analytic values. Finally, the ultimate bearing capacity of the specimen was verified by static loading test.
\end{abstract}

Keywords: PSC I-girder; railway bridge; medium span length; moving load analysis; dynamic characteristics

\section{Introduction}

Korea achieved remarkable growth of its transportation infrastructure within a very short period. The Korean government annually announces the current status of roads and railroad facilities $[1,2]$. Figure 1 is reconstructed using current status data for roads [1] and railroad facilities [2]. Figure 1a plots the evolution of the inventory of the road and railway bridges during the decade running from 2008 to 2018. As of 2018, the extension of the roadway and railway reaches $114,788 \mathrm{~km}$ in which 40,435 bridges occupy $4198 \mathrm{~km}$. Compared to 2008, 9129 new bridges were erected over $1238 \mathrm{~km}$ representing a $42 \%$ increase of the extension and a $29 \%$ increase of the bridge stock. In details, there are today 34,297 roadway bridges and 3138 railway bridges spanning over $3451 \mathrm{~km}$ and $747 \mathrm{~km}$, respectively (Figure 1b). 


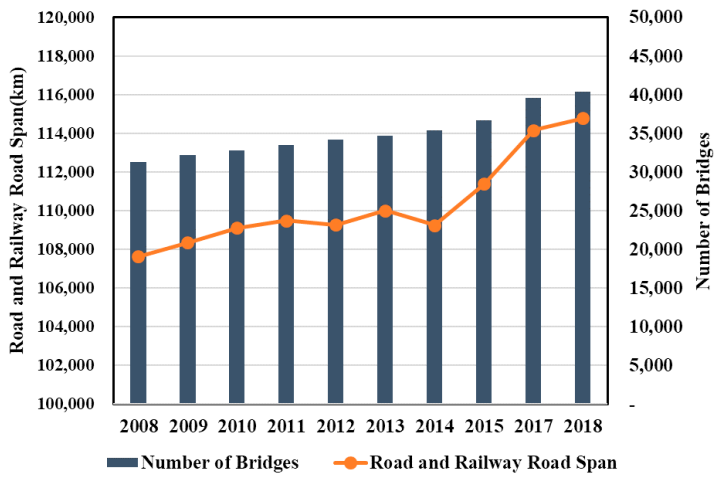

(a)

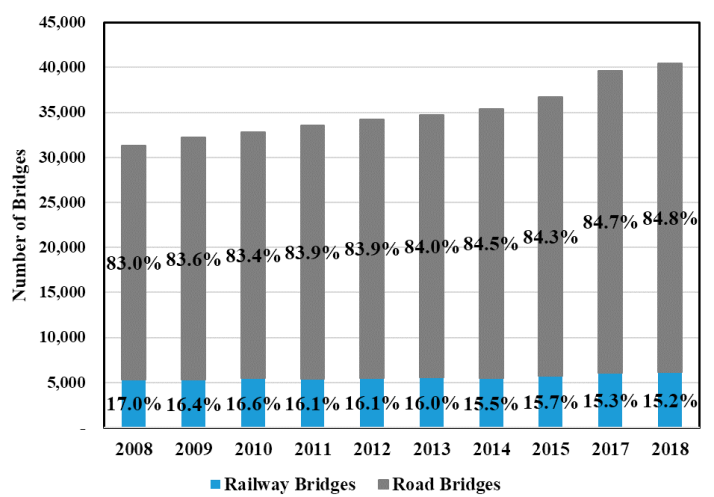

(b)

Figure 1. Evolution of transportation infrastructure in Korea: (a) total length and bridge inventory; (b) proportions of roadway and railway bridges.

Table 1 classifies the 34,297 roadway bridges according to the type of their structure and superstructure [1]. The most preferred superstructure types are the reinforced concrete (RC) slab bridge followed successively by the rahmen (rigid-frame) bridge, the prestressed concrete (PSC) I-girder bridge and the steel box girder bridge with rates of occupancy of $24.1 \%, 23.6 \%, 22.6 \%$ and $13.7 \%$, respectively. These four types of superstructure account for $84 \%$ of the bridge stock. According to Jung et al. [3], most of the bridge superstructures applied the RC slab and the RC T-girder in the 1950s, and the PSC I-girder became the preponderant type of superstructure after a peak in the 1960s owing to its low cost and shortened construction period. Figure 2a shows the domestic bridge market share of the PSC I-girder since 1970 and reveals that this share increased by an average of $36.2 \%$ between 2014 and 2018. Figure $2 \mathrm{~b}$ presents the change in the distribution of the span length for the PSC I-girder since its first introduction in the early 1960s. It can be observed that the PSC I-girder is currently preferred for medium span lengths between $30 \mathrm{~m}$ and $40 \mathrm{~m}$. Apart from special long-span bridges, the application of the PSC I-girder as superstructure is now common in Korea for its aesthetics and economy for usual span lengths $[4,5]$.

Table 1. Distribution of bridges by superstructure type in Korea.

\begin{tabular}{cccccc}
\hline Bridge Type & $\begin{array}{c}\text { Number of } \\
\text { Bridges }\end{array}$ & $\begin{array}{c}\text { Total Span } \\
\mathbf{( k m )}\end{array}$ & $\begin{array}{c}\text { Superstructure } \\
\text { Type }\end{array}$ & $\begin{array}{c}\text { Number of } \\
\text { Bridges }\end{array}$ & $\begin{array}{c}\text { Total Span } \\
(\mathbf{k m})\end{array}$ \\
\hline Suspension & 9 & 21.3 & RC slab & 8271 & 348.1 \\
\hline Cable-stayed & 69 & 74.3 & RC hollow slab & 238 & 22.1 \\
\hline Extradosed & 22 & 14.1 & RC box girder & 211 & 9.4 \\
\hline Truss & 17 & 8.9 & RC T-girder & 751 & 36.0 \\
\hline Internal & 8092 & 173.6 & PSC slab & 491 & 41.1 \\
\hline Arch & 226 & 40.7 & PSC hollow slab & 40 & 7.8 \\
\hline Steel plate girder & 307 & 61.2 & PSC box girder & 625 & 336.8 \\
\hline Steel box girder & 4705 & 1051.7 & PSC I-girder & 7768 & 1009.3 \\
\hline Steel I-girder & 201 & 23.1 & Preflex girder & 1362 & 88.4 \\
\hline Others & 892 & 83.6 & Total & 34,297 & 3451.5 \\
\hline
\end{tabular}

For the roadway bridges, the stiffness of the girder is a primary factor determining the structural stability. Besides, securing the dynamic stability under large live loads and repeated loading is the primary factor in the case of railway bridges. Accordingly, studies have been conducted recently on the 
development of dedicated monitoring systems as well as on the evaluation of the dynamic behavior of high-speed railway bridges [6-8].

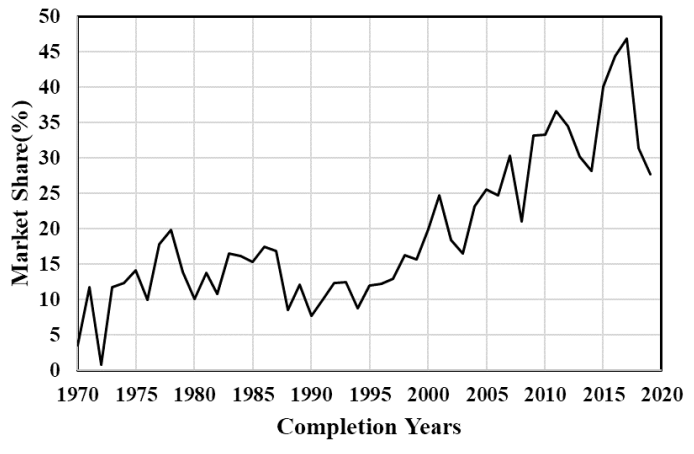

(a)

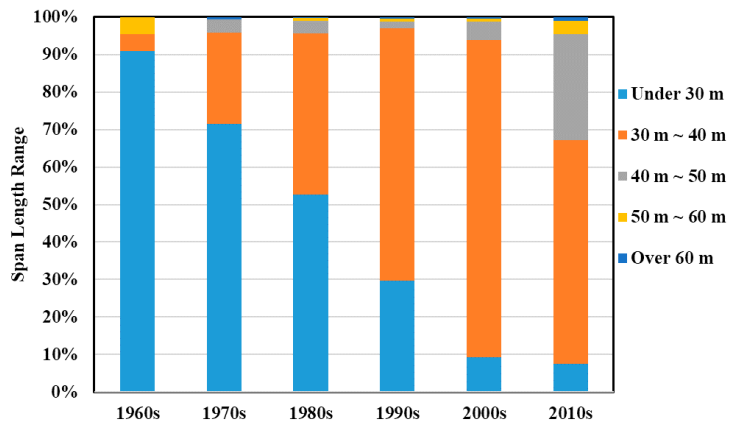

(b)

Figure 2. Yearly evolution of prestressed concrete (PSC) I-girder bridge inventory in Korea: (a) market share; (b) distribution per span length.

The present study intends to evaluate the structural behavior of a new type of PSC I-girder for its application to railway bridges. Since the I-girder exhibits relatively low torsional rigidity, it may produce large responses even under the natural frequencies for the same flexural mode because of its light weight, which necessitates precise evaluation of the dynamic stability [9]. The considered span length is decided based upon the analysis of the preferred span length in the design stage, and both analytical and experimental evaluations are carried out for the application of the new type of PSC I-girder in the railway bridge.

\section{Dynamic Performance Evaluation of New Type of PSC I-girder Bridge}

\subsection{Structure Considered in Analysis}

The new type of PSC I-girder considered in this study applies the half-slab to take full advantage of its characteristics in term of construction stability. The so-called half-slab girder of which upper flange plays the role of slab presents a reduced height thanks to the efficient arrangement of the prestressing tendon through the dualization of the anchors of the tendon by disposing intermediate anchors in addition to the end anchors as shown in Figure 3. Four different span lengths (30, 35, 40, $45 \mathrm{~m}$ ) of the girder were adopted considering recent trends in the span lengths for the PSC I-girder. Figure 3 depicts the longitudinal plan of the new type of PSC I-girder. The sectional dimensions were determined by applying the Korean standard train load KRL-2012 [10] for passenger car mixed line in the design. Figure 4 shows the section of PSC I-girder designed to sustain two railway lanes. Four girders are applied for the span lengths of $30 \mathrm{~m}$ and $35 \mathrm{~m}$, and five girders for the span lengths of $40 \mathrm{~m}$ and $45 \mathrm{~m}$. The height of the girder is set to $2.5 \mathrm{~m}$ for the span lengths of $30 \mathrm{~m}$ and $35 \mathrm{~m}, 2.7 \mathrm{~m}$ for the span length of $40 \mathrm{~m}$, and $3.2 \mathrm{~m}$ for the span length of $45 \mathrm{~m}$. The thickness of the slab is $280 \mathrm{~mm}$ including the $140 \mathrm{~mm}$-thick half-slab. Concrete track is adopted in the model. Table 2 arranges the material properties of the considered bridge. Concrete with compressive strength of $50 \mathrm{MPa}$ is adopted for the girder and concrete with compressive strength of $30 \mathrm{MPa}$ is adopted for the slab.

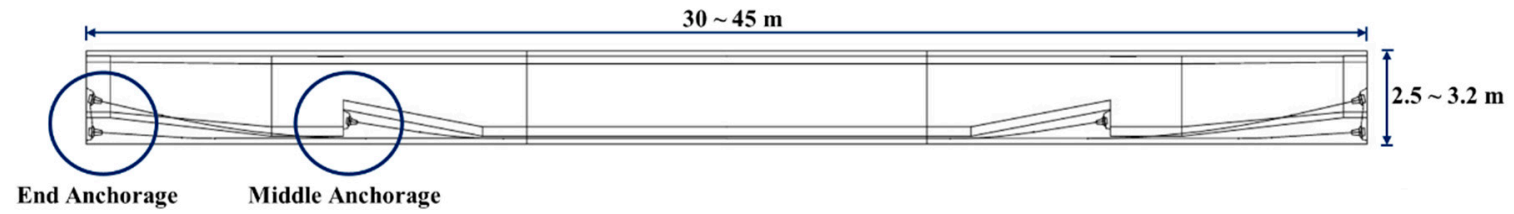

Figure 3. Longitudinal plan of railway bridge applying the new type of PSC I-girder. 


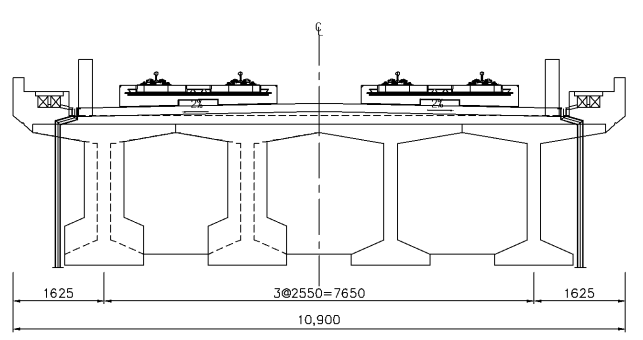

(a)

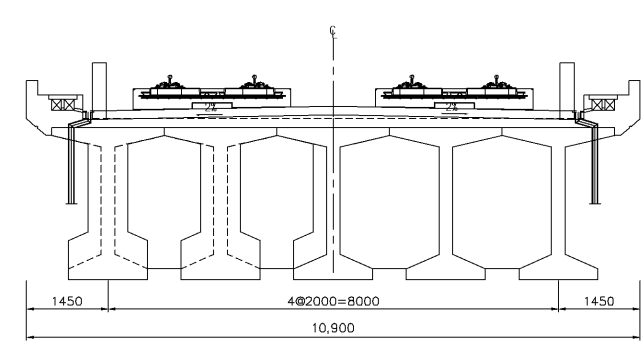

(b)

Figure 4. Front view of railway bridge section: (a) application of 4 girders for span lengths of $30 \mathrm{~m}$ and $35 \mathrm{~m}$; (b) application of 5 girders for span lengths of $40 \mathrm{~m}$ and $45 \mathrm{~m}$.

Table 2. Material properties of concrete.

\begin{tabular}{|c|c|c|c|c|}
\hline \multicolumn{2}{|c|}{ Compressive Strength (MPa) } & \multicolumn{2}{|c|}{ Young's Modulus (MPa) } & \multirow{2}{*}{ Density $\left(\mathrm{kN} / \mathrm{m}^{3}\right)$} \\
\hline Girder & Slab & Girder & Slab & \\
\hline 50 & 30 & 32.902 & 28.577 & 24.5 \\
\hline
\end{tabular}

\subsection{Performance Evaluation by Moving Load Analysis}

\subsubsection{Performance Evaluation Criteria}

Compared to the road bridge, the railway bridge experiences larger live loads and may suffer dynamic problems like resonance due to the cyclic loading generated by the train wheels traveling at high speed. The railway bridge must thus satisfy thorough vibration limits as well as vertical deflection limits. Accordingly, the railway design code (KDS 2410 10) requires to perform moving load analysis for the train load per range of traveling speed and to perform the evaluation of vertical acceleration, vertical deflection and twist of the bridge span in order to secure the dynamic stability of the railway bridge subjected to traveling trains. Table 3 details the limits for each check item specified in KDS 241010 [11].

Table 3. Railway bridge specifications for traveling safety and comfort (KSD 2410 10) [11].

\begin{tabular}{|c|c|c|c|}
\hline Item & \multicolumn{2}{|c|}{ Application } & Limit \\
\hline \multirow{2}{*}{ Vertical acceleration } & \multirow{2}{*}{\multicolumn{2}{|c|}{$\begin{array}{l}\text { Gravel ballast track } \\
\text { Concrete ballast track }\end{array}$}} & $0.35 \mathrm{~g}$ \\
\hline & & & $0.5 \mathrm{~g}$ \\
\hline \multirow{3}{*}{ Twist } & \multirow{2}{*}{ Standard train load } & $V \leq 200 \mathrm{~km} / \mathrm{h}$ & $3.0 \mathrm{~mm} / 3 \mathrm{~m}$ \\
\hline & & $V>200 \mathrm{~km} / \mathrm{h}$ & $1.5 \mathrm{~mm} / 3 \mathrm{~m}$ \\
\hline & \multicolumn{2}{|c|}{ Dynamic analysis with real train } & $1.2 \mathrm{~mm} / 3 \mathrm{~m}$ \\
\hline \multirow{12}{*}{ Vertical deflection } & \multirow{12}{*}{ Span length } & \multirow{3}{*}{$30 \mathrm{~m}$} & $L / 1600(270<V \leq 350)$ \\
\hline & & & $L / 1500(200<V \leq 270)$ \\
\hline & & & $L / 1300(V \leq 200)$ \\
\hline & & \multirow{3}{*}{$35 \mathrm{~m}$} & $L / 1750(270<V \leq 350)$ \\
\hline & & & $L / 1600(200<V \leq 270)$ \\
\hline & & & $L / 1500(V \leq 200)$ \\
\hline & & \multirow{3}{*}{$40 \mathrm{~m}$} & $L / 1900(270<V \leq 350)$ \\
\hline & & & $L / 1700(200<V \leq 270)$ \\
\hline & & & $L / 1500(V \leq 200)$ \\
\hline & & \multirow{3}{*}{$45 \mathrm{~m}$} & $L / 2100(270<V \leq 350)$ \\
\hline & & & $L / 1900(200<V \leq 270)$ \\
\hline & & & $L / 1400(V \leq 200)$ \\
\hline
\end{tabular}


The five different train loads listed in Table 4 were considered in the moving load analysis. These train loads correspond to those currently in operation or under plan. Here, the Saemaeul train and the freight train are conventional trains operating in the previous railway network and KTX (Korea Train eXpress) stands for the high-speed train. HEMU (Highspeed Electric Multiple Unit) and EMU (Electric Multiple Unit) are the high-speed trains of the next generation. Table 4 provides also the composition of the convoy, the size of the axle load and the effective beating interval for each of the considered trains. Figure 5 shows the KTX train, one of the five train models. Moving load analysis was performed at intervals of time until the train started from the point of the bridge and completely passed the bridge. At this time, the element was set to hit three or more times to ensure numerical stability.

Table 4. Characteristics of trains in operation or under plan in Korea.

\begin{tabular}{cccccc}
\hline \multirow{2}{*}{ Characteristics } & \multicolumn{3}{c}{ Train in Operation } & \multicolumn{2}{c}{ Train under Plan } \\
\cline { 2 - 6 } & KTX & Saemaeul & Freight & HEMU & EMU \\
\hline Composition & 20 coaches & 8 coaches & 20 coaches & 12 coaches & 8 coaches \\
Axle load $(\mathrm{kN})$ & $170 \sim 190$ & $107.91 \sim 215.82$ & 196.2 & 130 & 156.8 \\
Effective beating interval $(\mathrm{m})$ & 18.7 & 23.5 & 13.95 & 24.3 & 21.4 \\
Max. speed for analysis $(\mathrm{km} / \mathrm{h})$ & 420 & 300 & 220 & 430 & 330 \\
\hline
\end{tabular}

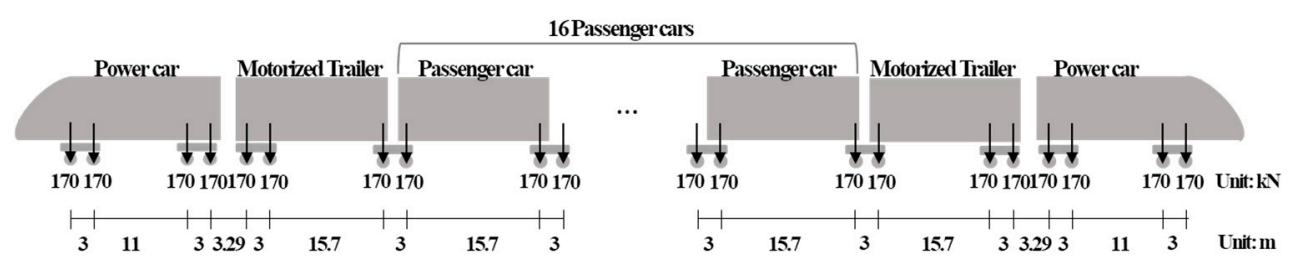

Figure 5. KTX Train.

The occurrence of resonance or resonance suppression in the railway bridge depends on the relationship existing between the effective beating interval and the span length [12-14]. Resonance occurs when the natural frequency of the bridge coincides with the frequency of the force vibration generated by the periodic beating of the regularly spaced axles of the train. The critical speed $\left(V_{c r}\right)$ of the train causing resonance can be calculated by Equation (1) [11], where $V_{s c r}$ is the sub-critical speed; $w_{1}$ is the natural frequency of the first flexural mode of the bridge; and, $S_{\text {eff }}$ is the effective beating interval of the train load as given in Table 4. Moreover, the sub-critical speed is obtained as an integer ratio of the critical speed as expressed in Equation (2). Besides, resonance suppression is conceptually opposite to resonance that deals with the suppression of the free vibration effect of the bridge caused by the traveling train. In other words, resonance suppression is a phenomenon that occurs when the dynamic response of the bridge is determined only by the load currently positioned in the bridge [14]. Equation (3) gives the span length $L(\mathrm{~m})$ of the bridge for which resonance suppression occurs.

$$
\begin{gathered}
V_{c r}=w_{1} \times S_{e f f}, \\
V_{s c r}=\frac{w_{1}}{n} \times S_{e f f}, n=1,2,3, \cdots \\
L(\mathrm{~m})=S_{e f f} \times(i+0.5), i=1,2,3, \cdots
\end{gathered}
$$

The fact that the resonance suppression span length is determined with respect to the effective beating interval of the train indicates the existence of a span length for which the response at resonance is suppressed according to the train type. Figure 6 plots the resonance suppression span length provided by Equation (3) for each of the five considered trains. 


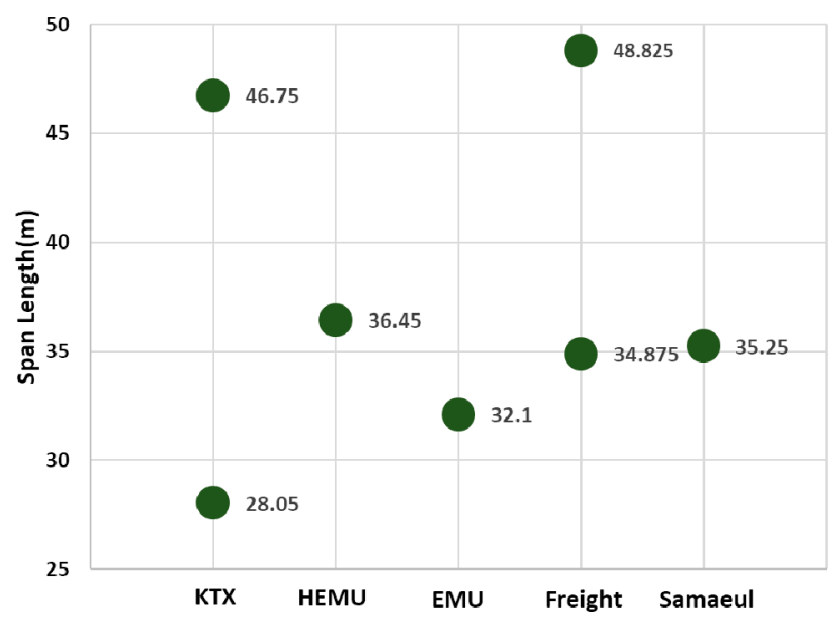

Figure 6. Resonance suppression span length per type of train.

Accounting that the PSC I-girder is mostly applied to span lengths between $30 \mathrm{~m}$ and $40 \mathrm{~m}$ (Figure 2), the span length of $35 \mathrm{~m}$ appears to be the most favorable in term of resonance suppression. Consequently, this span length of $35 \mathrm{~m}$ is expected to develop small response under the traveling trains. Due to the discrepancy with the resonance suppression span length for KTX, evaluating the behavior of the bridge by moving load analysis will bear utmost importance. Besides, the span length of $30 \mathrm{~m}$ is the closest to the resonance suppression span length for KTX. In such a case, it will be necessary to conduct precise moving load analysis for HEMU and EMU. In addition, the satisfaction of the design criteria including the acceleration, displacement and twist for each of the train loads shall be checked by dynamic analysis.

\subsubsection{Analysis Method}

The dynamic moving load analysis is carried out using the in-house programs HFC and hfAnalyzer developed at Korea Institute of Civil Engineering and Building Technology (KICT). HFC is a kind of library designed by object-oriented programming that allows the user to implant his/her own material model and analysis method. The hfAnalyzer was developed using HFC and its applicability has been validated by applying various modeling and analysis methods on diversified railway bridges [9]. The model adopts 2-node beam elements for the girder and cross beams to reflect the features of the girder bridge and 4-node shell elements for the deck. The concrete ballast track composed of PCL (protection concrete layer) and TCL (track concrete layer) is also reflected in the model to achieve accurate analysis. Specifically, the PCL is modeled as a distributed mass load and TCL is modeled by solid elements. The rails are modeled by 2-node beam elements to consider the entrance and exit of the traveling train on the bridge. For the bridge bearings, beam-type restraints are applied with deck considering the gap with the girders. Figure 7 depicts the analytical FE model for the girder bridge with span length of $35 \mathrm{~m}$. The damping ratio in the moving load analysis has the most sensitive effect on the amplitude of the response of the bridge at resonance. Therefore, this study applies a damping ratio of 1\% as suggested in the Railway Design Code (KDS 2410 10) [10,11].

The moving load analysis was carried out for the train since its access on the structure to its complete crossing for traveling speeds increased by step of $10 \mathrm{~km} / \mathrm{h}$ within the maximum speed range and including the critical and sub-critical speeds listed in Table 4. The train load was applied on one line to consider the effect of eccentric loading, and the amplitudes of the vertical deflection, vertical acceleration of the deck as well the twist of the track were checked. 


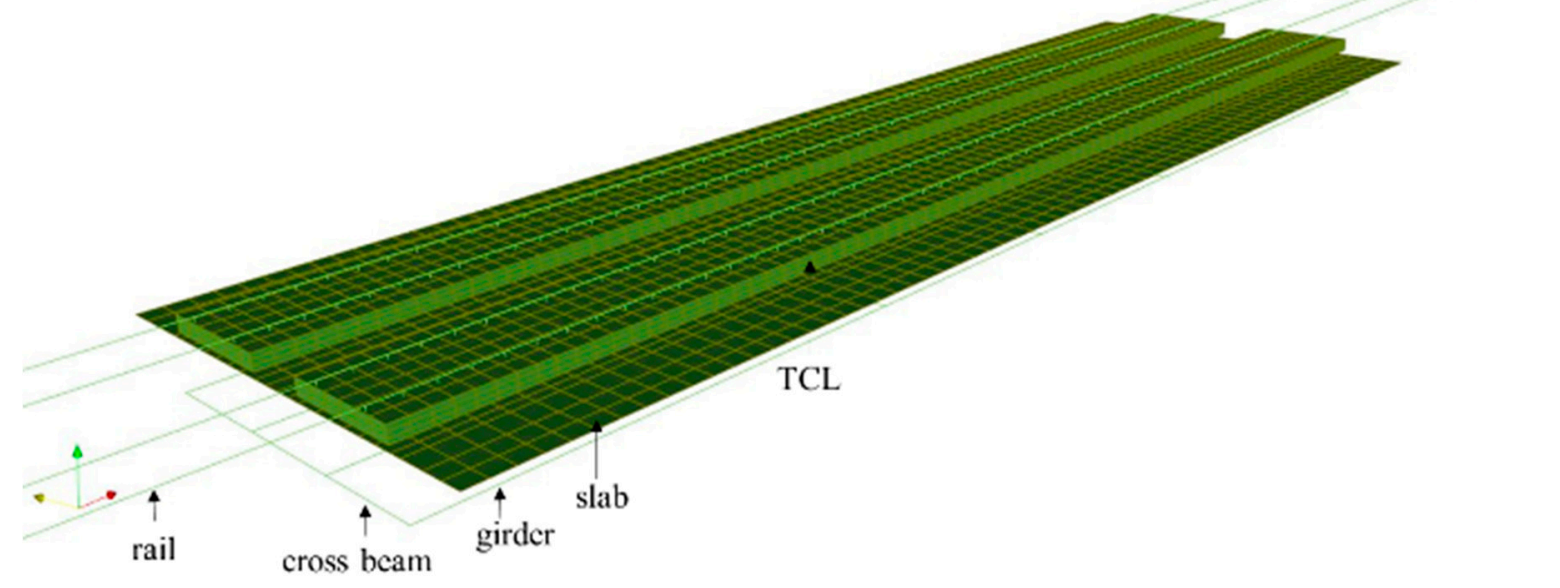

Figure 7. Model of PSC I-girder railway bridge with two traffic lines for moving load analysis.

\subsection{Dynamic Performance Evaluation of New PSC I-girder Bridge}

\subsubsection{Natural Frequencies}

Since the I-girder develops lower torsional rigidity than the box girder, its torsional mode will occur at proximity of the flexural mode in the lower order mode range, which presents the risk for these two modes to superpose and amplify the responses [9]. Table 5 lists the natural frequencies of the PSC I-girder bridge with the corresponding mode according to the type of train with their critical speeds per considered span length of the bridge. The first flexural mode appears to be the first mode for the span lengths of $35 \mathrm{~m}$ and $40 \mathrm{~m}$ whereas the first mode for the span lengths of $30 \mathrm{~m}$ and $45 \mathrm{~m}$ is the torsional mode. In addition, when the first mode is the flexural mode, the second mode is the torsional mode and happens closely. Figure 8; Figure 9 shows the first and second mode shapes for the span lengths of $30 \mathrm{~m}$ and $35 \mathrm{~m}$. The first flexural mode related to the critical speed ranges between $3.39 \mathrm{~Hz}$ and $4.5 \mathrm{~Hz}$.

Table 5. Analytically obtained natural frequencies and critical speeds per train type.

\begin{tabular}{cccccccc}
\hline \multirow{2}{*}{$\begin{array}{c}\text { Span } \\
\text { Length }\end{array}$} & Mode & \multirow{2}{*}{$\begin{array}{c}\text { Natural } \\
\text { Freq. (Hz) }\end{array}$} & KTX & HEMU & EMU & Freight & Saemaeul \\
\cline { 4 - 7 } & & & & \multicolumn{5}{c}{ Critical Speeds (km/h) } \\
& 1(Torsion) & 4.14 & 278.81 & 362.31 & 319.07 & 207.99 & 350.38 \\
\multirow{3}{*}{$30 \mathrm{~m}$} & 2(Flexure) & 4.50 & 302.73 & 393.39 & 346.44 & 225.83 & 380.44 \\
& 3(Torsion) & 7.16 & 482.26 & 626.68 & 551.89 & 359.76 & 606.05 \\
& 4(Torsion) & 12.74 & 857.66 & 1114.50 & 981.49 & 639.80 & 1077.80 \\
\hline \multirow{3}{*}{$35 \mathrm{~m}$} & 1(Flexure) & 4.27 & 288.02 & 374.27 & 329.60 & 214.86 & 361.95 \\
& 2(Torsion) & 4.67 & 314.87 & 409.16 & 360.33 & 234.89 & 395.69 \\
& 3(Torsion) & 8.21 & 552.79 & 718.33 & 632.60 & 412.38 & 694.68 \\
& 4(Torsion) & 13.14 & 885.10 & 1150.16 & 1012.90 & 660.28 & 1112.30 \\
\hline \multirow{3}{*}{$40 \mathrm{~m}$} & 1(Flexure) & 3.56 & 239.92 & 311.77 & 274.56 & 178.98 & 301.51 \\
& 2(Torsion) & 3.76 & 253.23 & 329.06 & 289.79 & 188.91 & 318.23 \\
& 3(Torsion) & 7.70 & 518.63 & 673.95 & 593.52 & 386.89 & 651.76 \\
& 4(Torsion) & 11.35 & 763.81 & 992.55 & 874.10 & 569.80 & 959.87 \\
\hline \multirow{3}{*}{$45 \mathrm{~m}$} & 1(Torsion) & 3.29 & 221.51 & 287.84 & 253.49 & 165.24 & 278.37 \\
& 2(Flexure) & 3.39 & 228.47 & 296.89 & 261.46 & 170.44 & 287.11 \\
& 3(Torsion) & 7.66 & 515.39 & 669.73 & 589.80 & 384.47 & 647.68 \\
& 4(Torsion) & 10.12 & 681.48 & 885.56 & 779.88 & 508.38 & 856.41 \\
\hline
\end{tabular}




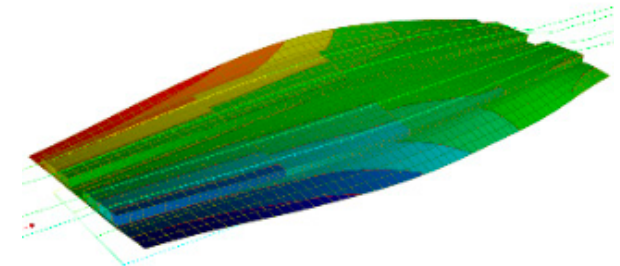

(a)

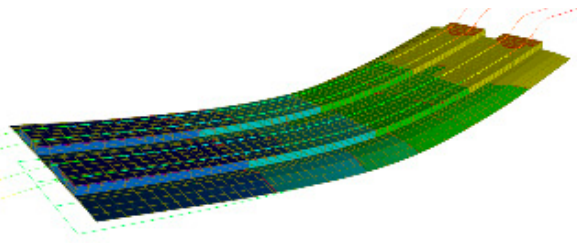

(b)

Figure 8. Vibration modes for span length of $30 \mathrm{~m}$ : (a) first mode (torsion); (b) second mode (flexure).

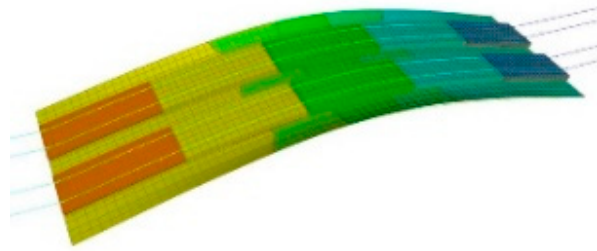

(a)

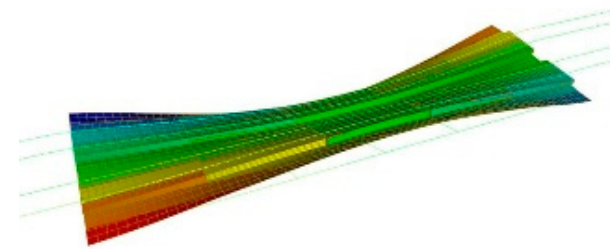

(b)

Figure 9. Vibration modes for span length of $35 \mathrm{~m}$ : (a) first mode (flexure); (b) second mode (torsion).

\subsubsection{Dynamic Stability Check}

This section analyzes the vertical acceleration (Figures 10a, 11a, 12a, 13a), vertical deflection (Figures 10b, 11b, 12b, 13b) and twist (Figures 10c, 11c, 12c, 13c) responses of the bridge deck obtained by moving load analysis. As a matter of fact, the largest vertical acceleration and deflection responses occur at mid-span. Besides, the maximum twist occurs at the position of the rails at spacing of $3 \mathrm{~m}$ in the longitudinal direction when the rails are distant by $1.5 \mathrm{~m}$ as suggested by the Railway Design Code. The governing response related to the vertical acceleration is seen to happen nearby the critical speed or the sub-critical speed corresponding to the first flexural mode. On the other hand, the maximum vertical acceleration in the $35 \mathrm{~m}$-bridge under HEMU is observed at $390.0 \mathrm{~km} / \mathrm{h}$ between the speed of $374.27 \mathrm{~km} / \mathrm{h}$ corresponding to the first flexural mode and the speed of $409.16 \mathrm{~km} / \mathrm{h}$ corresponding to the first torsional mode. This result seems to indicate superposition of the response due to the proximity of the flexural and torsional modes. Nevertheless, the vertical acceleration response in the analyzed bridges according to the speed of the considered trains satisfied the design limits. The vertical displacement response appears to be mostly governed by the freight train regardless of the span length of the bridge. Moreover, the response with respect to the speed per type of train is observed to be the largest at the critical speed or the sub-critical speed corresponding to the first flexural mode. Here also, the vertical displacement response in the analyzed bridges according to the speed of the considered trains satisfied the design limits. Furthermore, the twist response seems also to be mostly governed by the freight train regardless of the span length of the bridge and satisfied the design limits. 


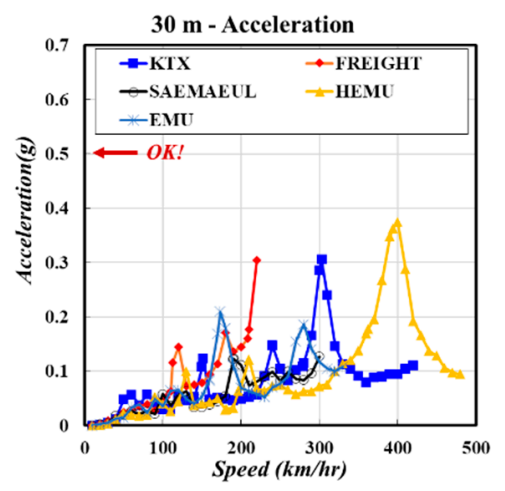

(a)

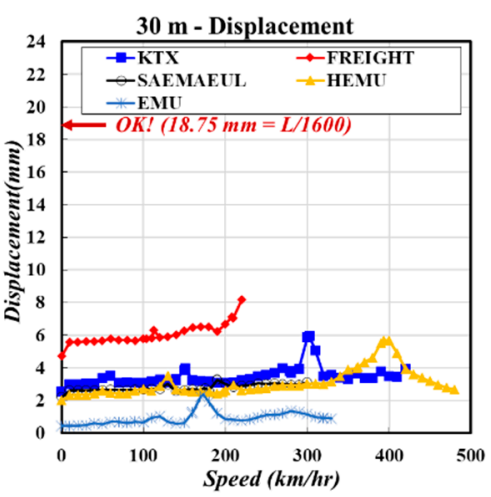

(b)

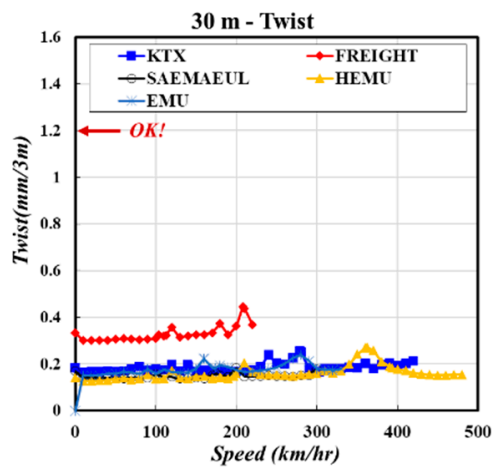

(c)

Figure 10. Moving load analysis results for span length of $30 \mathrm{~m}$ : (a) vertical acceleration response; (b) vertical displacement response; and (c) twist response.

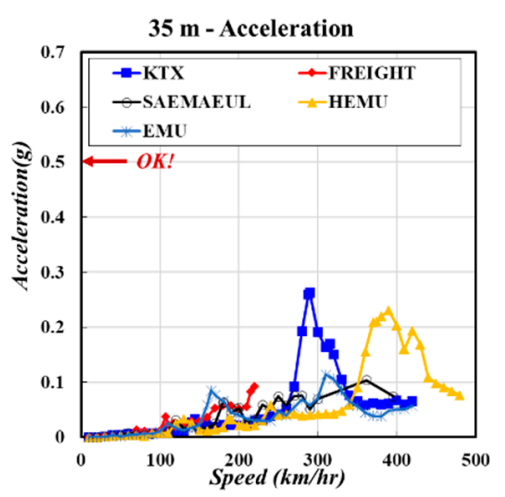

(a)

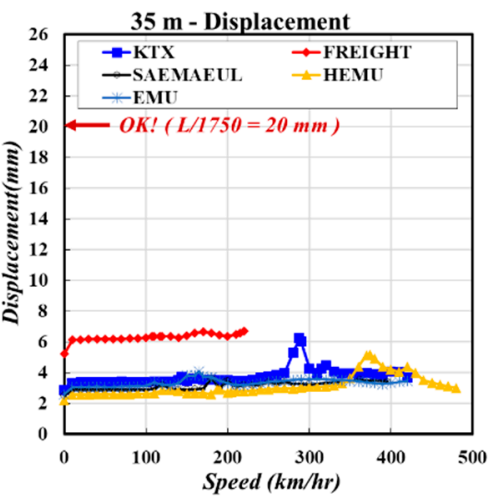

(b)

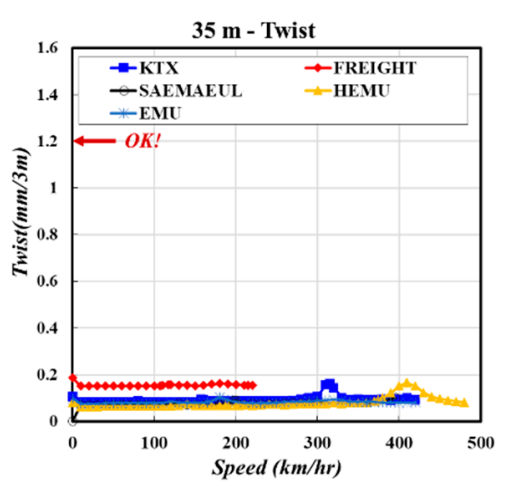

(c)

Figure 11. Moving load analysis results for span length of $35 \mathrm{~m}$ : (a) vertical acceleration response; (b) vertical displacement response; and (c) twist response.

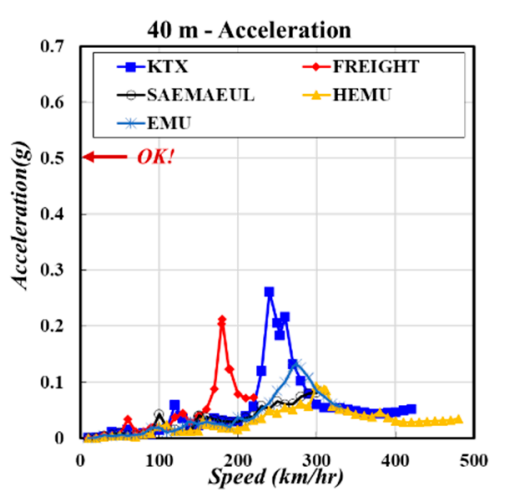

(a)

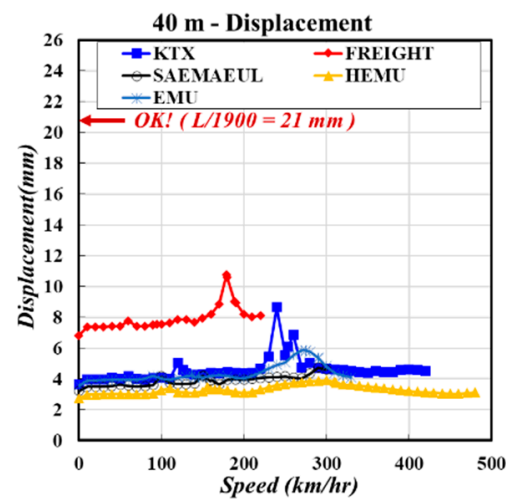

(b)

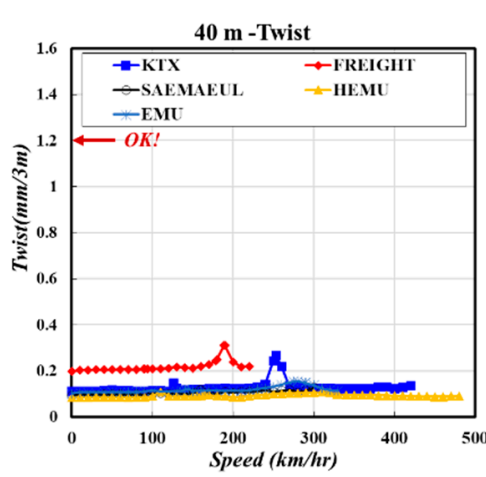

(c)

Figure 12. Moving load analysis results for span length of $40 \mathrm{~m}$ : (a) vertical acceleration response; (b) vertical displacement response; and (c) twist response. 


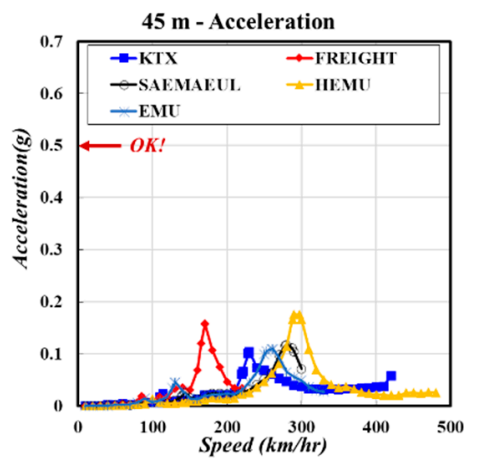

(a)

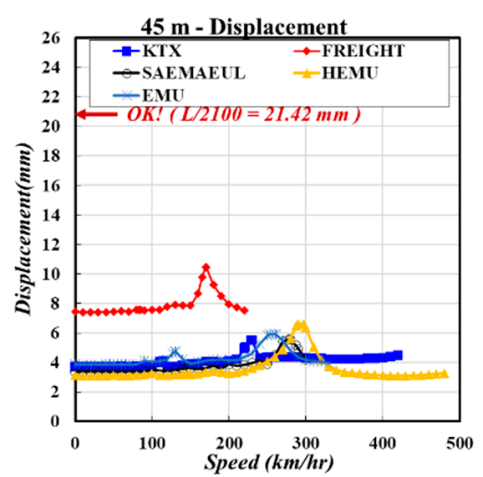

(b)

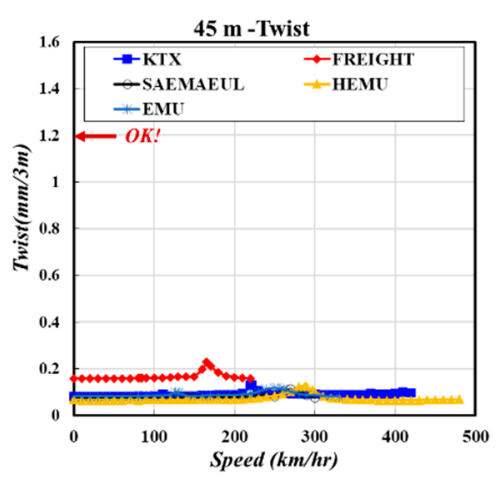

(c)

Figure 13. Moving load analysis results for span length of $45 \mathrm{~m}$ : (a) vertical acceleration response; (b) vertical displacement response; and (c) twist response.

\section{Performance Evaluation on Full-Scale PSC I-girder Specimen}

\subsection{Full-Scale PSC I-girder Specimen}

A full-scale specimen of the PSC I-girder was fabricated to check the validity of the values applied for the damping ratio and the natural frequencies as governing factors on the amplitude of the dynamic responses. In addition to the dynamic test, static test was also performed to evaluate the load bearing capacity of the girder. The specimen of which dimensions are shown in Figure 14 was fabricated to span over $35 \mathrm{~m}$ among the 4 considered span lengths. Note that cuttings were done in the bottom of the girder at a longitudinal distance of $1100 \mathrm{~mm}$ from the ends to prevent the occurrence of overturning during the transportation and construction process of the PSC I-girder. The height of the girder including the $140 \mathrm{~mm}$ of the half-deck is $2.5 \mathrm{~m}$. The concretes used for the specimen apply the values listed in Table 2, which is a compressive strength of $50 \mathrm{MPa}$ for the girder and $30 \mathrm{MPa}$ for the deck. The specimen was fabricated in 3 segments $(12+10.9+12 \mathrm{~m})$ aligned longitudinally and assembled by post-tensioning. Finally, a monolithic structure was obtained by placing the deck concrete.

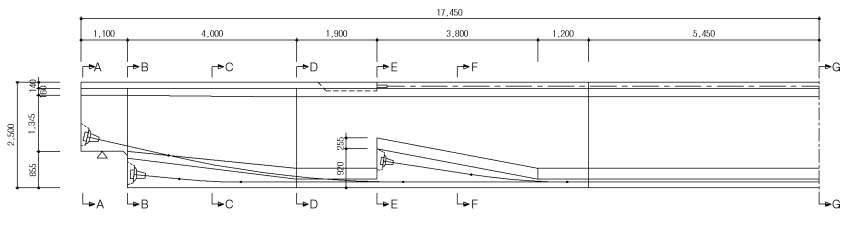

(a)

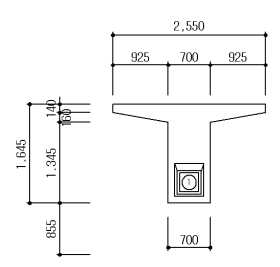

(b)

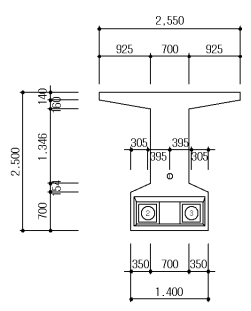

(c)

Figure 14. Shape of $35 \mathrm{~m}$-long full-scale PSC I-girder specimen: (a) longitudinal view with 3 segments $(12+10.9+12 \mathrm{~m})$; (b) sectional view (A-A); and (c) sectional view (B-B).

\subsection{Evaluation of Dynamic Characteristics}

The dynamic test was conducted to verify the validity of the analytical model in Section 2. The natural frequencies of the specimen were compared to the values obtained by moving load analysis. Forced vibration was applied using the exciter shown Figure 15a and by impact through manpower as shown in Figure 15b. 


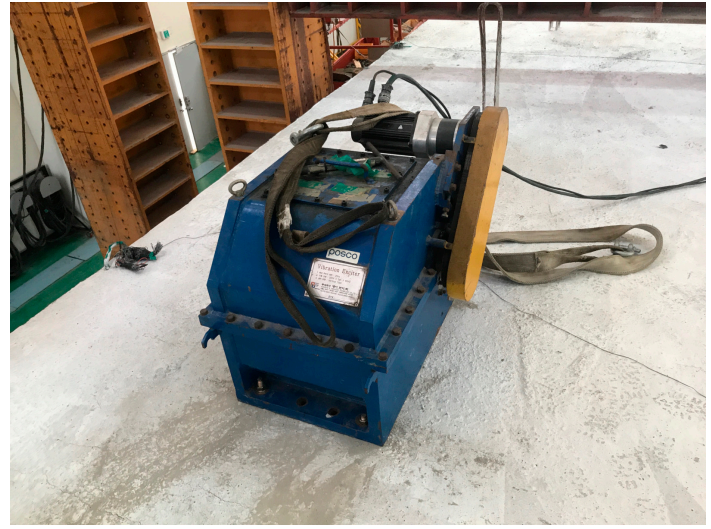

(a)

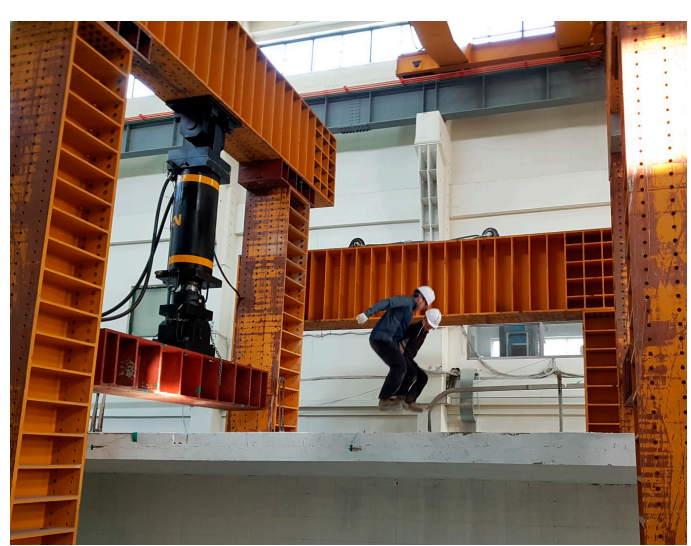

(b)

Figure 15. Forced vibration methods: (a) exciter; (b) manpower.

For the vibration caused by the exciter, the frequency of the forcing excitation was increased stepwise and the behavior of the specimen was observed. Figure 16a plots the acceleration measured at the bottom of the girder. The largest amplitude of the acceleration occurred under excitation frequencies between $4.2 \mathrm{~Hz}$ and $4.4 \mathrm{~Hz}$. After having roughly verified the range of the natural frequency of the specimen, impact test was conducted by two men jumping on the girder as shown in Figure $15 \mathrm{~b}$ to generate free vibration and check the natural frequency. FFT (Fast Fourier Transform) analysis was then performed on the vertical acceleration data acquired during the free vibration of the girder as shown in Figure 16b. The so-obtained natural frequency was $4.2 \mathrm{~Hz}$, which agreed fairly with the analytic value of $4.27 \mathrm{~Hz}$ for the span length of $35 \mathrm{~m}$. Figure 16c plots the residual vertical displacement from which a damping ratio higher than $1 \%$ was estimated by curve fitting. Accordingly, the value of $1 \%$ adopted in the dynamic analysis can be assumed to be valid for the conservative design of the PSC I-girder railway bridge.

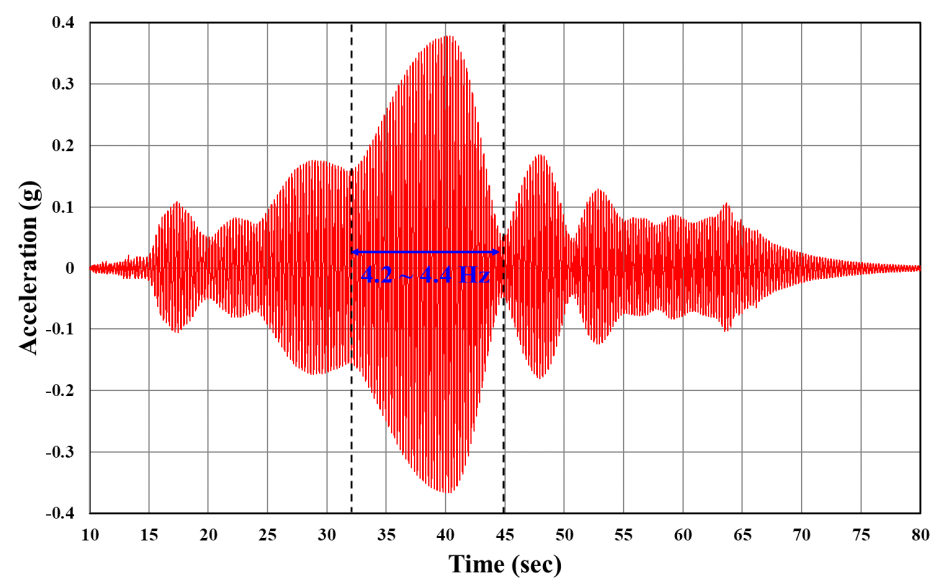

(a)

Figure 16. Cont. 


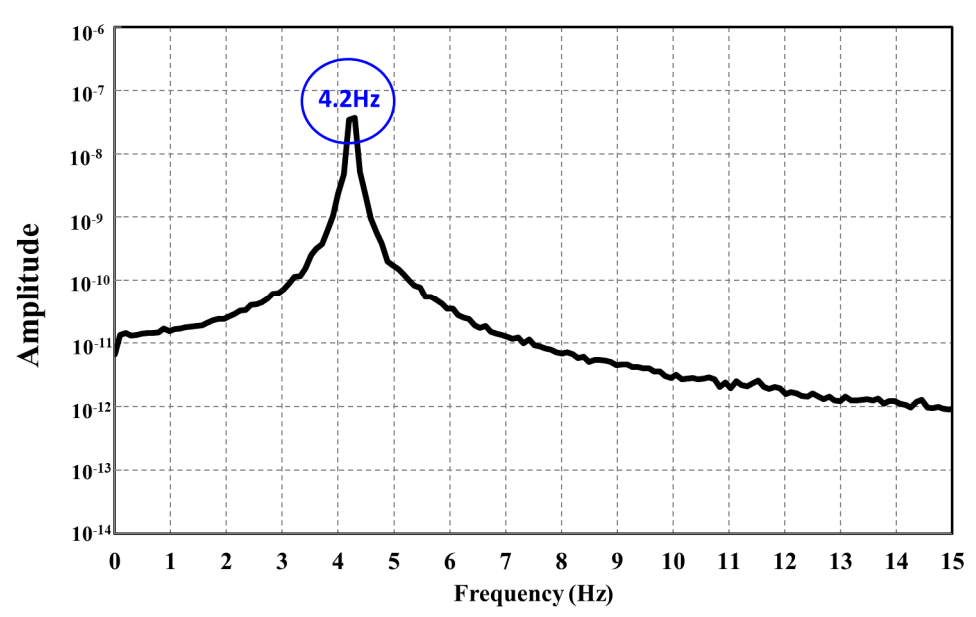

(b)

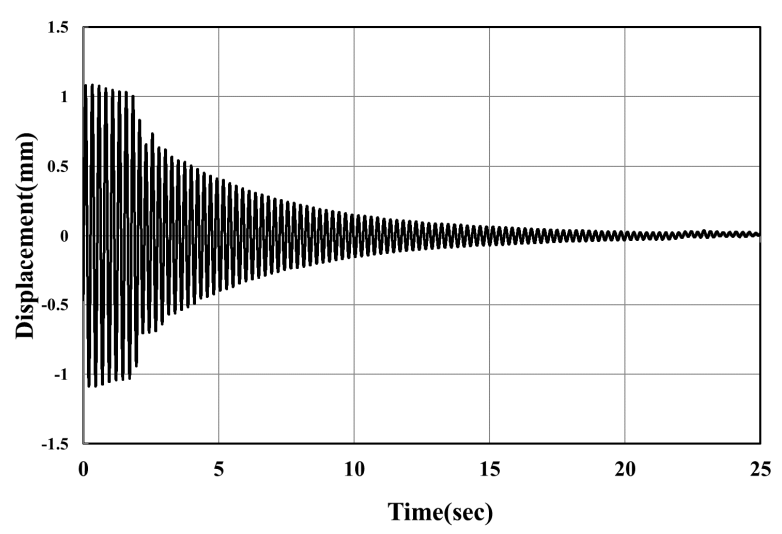

(c)

Figure 16. Dynamic characteristics of PSC I-girder specimen: (a) acceleration response under forced vibration by exciter; (b) FFT analysis; and (c) free vibration for analysis of damping ratio.

\subsection{Evaluation of Ultimate Load Bearing Capacity}

\subsubsection{Test Method}

Four-point bending test was carried out on the specimen to evaluate its structural performance. Figure 17 illustrates the four-point bending test setup. The specimen was placed on two supporting pins positioned at a distance of $500 \mathrm{~mm}$ from the ends. Two loading actuators were placed at an equal $3 \mathrm{~m}$ apart from center of specimen, which let this distance be subjected to pure bending moment. Two actuators with capacity of $3500 \mathrm{kN}$ were used to apply loading and, the deflection, the strains in concrete and steel as well as the crack width at the segmental interfaces were measured. The test was planned to apply loading from the service load to the ultimate load and up to failure but failure could not be attained due to the limited capacity of the actuators and the maximum load reached $6097 \mathrm{kN}$. 


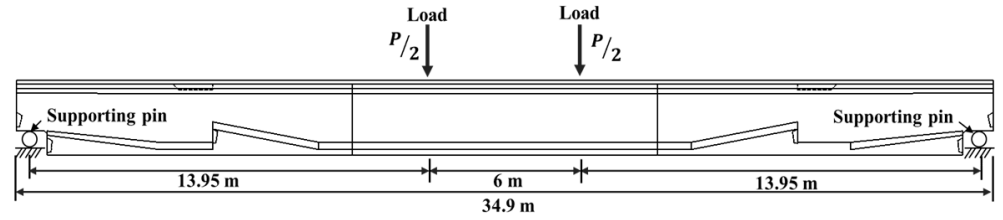

(a)

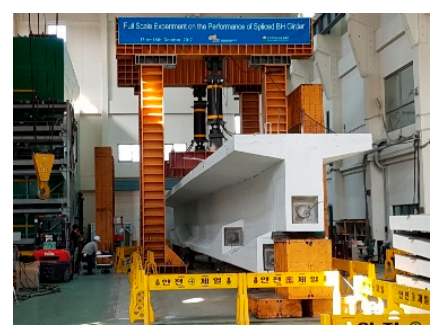

(b)

Figure 17. Static loading test of PSC I-girder: (a) 4-point bending test set up; (b) photograph of actual test.

\subsubsection{Test Results}

Figure 18 shows the crack map of the specimen at the maximum load of $6097 \mathrm{kN}$. Cracking initiated at the bottom in the center of the girder at $2530 \mathrm{kN}$. In view of the cracking pattern, the specimen exhibited typical flexural behavior until the maximum load.

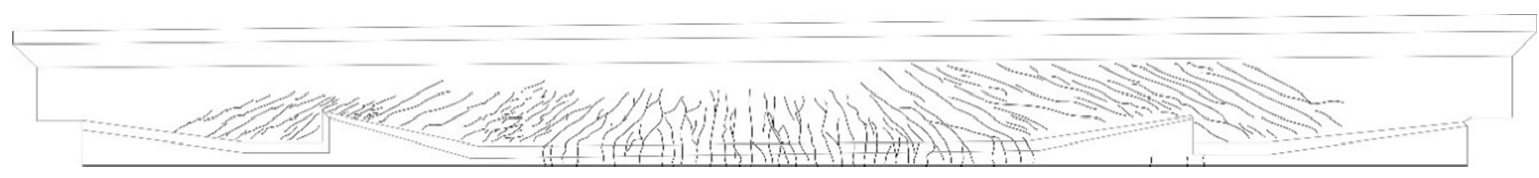

Figure 18. Crack map of specimen at maximum load.

The structural performance of the specimen was evaluated by comparing the experimental values with the load and deflection at ultimate limit state caused by the live load specified in the design code. Figure 19a,b plot respectively the deflection at mid-span and the crack width according to the increase of the load. Table 6 arranges the flexural performance requirements at service limit state and ultimate limit state provided by the design code. Note that the flexural performance here relates only to the live load. Table 6 also summarizes the amplitude of the load corresponding to each limit state and the corresponding vertical deflection measured in the specimen. The amplitude of the load at service limit state and ultimate limit state was calculated based upon the flexural strength deduced from the design code and the distance from the support to the loading point $(13.95 \mathrm{~m})$. As a result, the vertical deflection measured at the maximum load $(6097 \mathrm{kN})$ was $361 \mathrm{~mm}$, which provided vertical deflection of $43 \mathrm{~mm}$ for the ultimate limit state $(2150 \mathrm{kN})$ and $21.9 \mathrm{~mm}$ for the service limit state $(1162 \mathrm{kN})$.

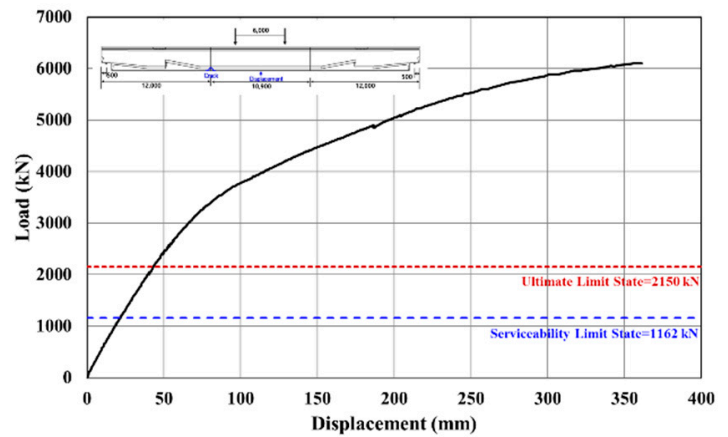

(a)

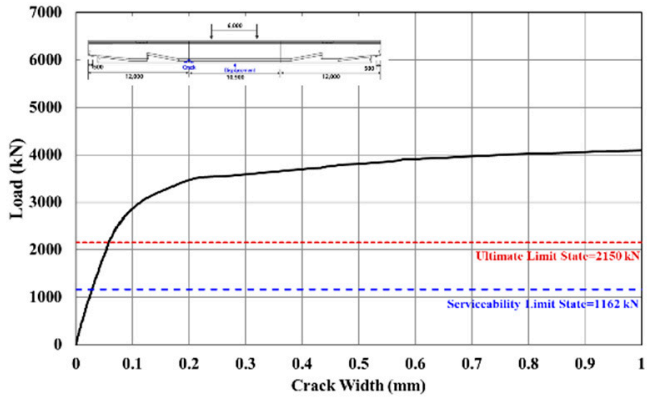

(b)

Figure 19. Results of static test of specimen: (a) load-displacement curve; (b) load-crack width curve. 
Table 6. Section forces and loads according to limit states.

\begin{tabular}{ccccccc}
\hline \multirow{2}{*}{$\begin{array}{c}\text { Maximum Load } \\
\text { at Experiment } \\
(\mathbf{k N})\end{array}$} & $\begin{array}{c}\text { Flexural } \\
\text { Strength } \\
(\mathbf{k N}-\mathbf{m})\end{array}$ & $\begin{array}{c}\text { Load } \\
\mathbf{( k N )}\end{array}$ & $\begin{array}{c}\text { Deflection } \\
\mathbf{( m m )}\end{array}$ & $\begin{array}{c}\text { Flexural } \\
\text { Strength } \\
(\mathbf{k N}-\mathbf{m})\end{array}$ & $\begin{array}{c}\text { Load } \\
\mathbf{( k N )}\end{array}$ & $\begin{array}{c}\text { Deflection } \\
(\mathbf{m m})\end{array}$ \\
\hline 6097 & 8105 & 1162 & 21.9 & 14,995 & 2150 & 43 \\
\hline
\end{tabular}

Even if the static test could not be conducted until failure and was terminated at the maximum load of $6097 \mathrm{kN}$ due to the limited capacity of the actuators, the specimen appears to secure sufficient safety factor considering the loads at service limit state and ultimate limit state. The corresponding vertical deflections also satisfied sufficiently the design limit $(L / 600=56.5 \mathrm{~mm})$. Moreover, the crack width measured at the segment interfaces at each limit state fell below the allowable crack width of $0.2 \mathrm{~mm}$ specified in the design code. Consequently, the segmentally fabricated specimen showed monolithic behavior.

\section{Conclusions}

This study presents the yearly evolution of bridges, especially PSC I-girder bridges in Korea and investigates analytically and experimentally the performance of the new PSC I-girder bridge to be applied as railway bridges. The following conclusions can be drawn.

(1) Natural frequency analysis for the new PSC I-girder range from a span of 30 to $45 \mathrm{~m}$ revealed that their first and second mode occur very close, either in bending or torsion mode alternately.

(2) Subsequent moving load analysis was conducted considering 5 types of trains in Korea. The new type of PSC I girder is likely to amplify the dynamic response due to the proximity of the first two modes, but it was found that it satisfied sufficiently all the design limits related to the acceleration, deflection and twist.

(3) Experimental verification of natural frequency was carried out on a full-scale specimen with span length of $35 \mathrm{~m}$. The natural frequency $(4.2 \mathrm{~Hz})$ of the specimen extracted from the dynamic test results was in good agreement with the value $(4.27 \mathrm{~Hz})$ obtained analytically and validated the dynamic analysis model established in this study.

(4) The performance of the specimen observed in the static test secured sufficient safety through the comparison of the load and deflection corresponding to the service and ultimate limit states of the design code. Accordingly, the new PSC I-girder presented in this study develops the dynamic performance and load bearing capacity required for its application in railway bridges and can be applied in new constructions under plan in Korea.

Author Contributions: H.Y. conceived the main idea and prepared this article as the first author; J.-R.C. reviewed the dynamic response. S.T.K., W.J.C. and Y.J.K. designed and performed the experiment. W.J.C. revised and finalized the paper. All authors have read and agreed to the published version of the manuscript.

Funding: This research was supported by “Development of Detection Technology for Internal Void of Tendon Duct of PSC Bridge (20200598-001)" and "A Performance Evaluation on the Segmental BH Girder System (20170442-001)" funded by Korea Institute of Civil engineering and building Technology (KICT), Korea.

Conflicts of Interest: The authors declare no conflict of interest.

\section{References}

1. Ministry of Land, Infrastructure and Transport. Yearbook of Road Bridge and Tunnel Statistics; Ministry of Land, Infrastructure and Transport: Sejong, Korea, 2019.

2. Railway Industry Information Center. Available online: http://www.kric.go.kr/jsp/industry/rss/installlineList. jsp?q_fdate=2018 (accessed on 11 November 2020). 
3. Jung, W.T.; Kim, Y.J.; Kang, J.Y.; Park, J.S. State-of-the-practice of constructed bridges in Korea. Proc. Inst. Civil Eng.-Struc. Build. 2018, 171, 705-718. [CrossRef]

4. Bae, K.-M.; Min, K.-H.; Lee, C.-O.; Lim, N.-H. Analysis and improvement of long-term deflection of PSC I girder for railway bridges. J. Korean Soc. Hazard Mitig. 2017, 17, 9-15. [CrossRef]

5. Lee, J.; Kim, S.; Kwark, J.; Lee, P.; Yoon, T. Dynamic characteristics of high-speed railway steel bridges. Trans. Korean Soc. Noise Vib. Eng. 2007, 17, 632-637. (In Korean)

6. Hajializadeh, D.; Žnidarič, A.; Kalin, J.; O’Brien, E.J. Development and testing of a railway bridge weigh-in-motion system. Appl. Sci. 2020, 10, 4708. [CrossRef]

7. Jiang, H.; Gao, L. Analysis of the vibration characteristics of ballastless track on bridges using an energy method. Appl. Sci. 2020, 10, 2289. [CrossRef]

8. Kaloop, M.R.; Hu, J.W.; Elbeltagi, E. Evaluation of high-speed railway bridges based on a nondestructive monitoring system. Appl. Sci. 2016, 6, 24. [CrossRef]

9. Cho, J.-R.; Kim, D.; Kim, Y.J.; Kwark, J.-W.; Jang, S.Y. Three dimensional model for dynamic moving load analysis of a PSC-I girder railway bridge. J. Korean Soc. Railw. 2013, 16, 286-297. [CrossRef]

10. Ministry of Land, Infrastructure and Transport. Bridge Design Loads-General Design Method (KDS 2412 20:2018); Ministry of Land, Infrastructure and Transport: Sejong, Korea, 2018. (In Korean)

11. Ministry of Land, Infrastructure and Transport. Bridge Design-General Design Method (KDS 24 10 10:2018); Ministry of Land, Infrastructure and Transport: Sejong, Korea, 2018. (In Korean)

12. Wakui, H.; Matsumoto, N.; Watanabe, T. Design impact factor for concrete railway bridges. Q. Rep. 1989, 30, 89-96.

13. Yang, Y.B.; Yau, J.D.; Hsu, L.C. Vibration of simple beams due to trains moving at high speeds. Eng. Struct. 1997, 19, 936-944. [CrossRef]

14. Kim, S.; Chung, W.; Choi, E. A study on the optimal span length selection of conventional railway bridges considering resonance suppression. J. Korean Soc. Railw. 2005, 8, 137-144.

Publisher's Note: MDPI stays neutral with regard to jurisdictional claims in published maps and institutional affiliations.

(C) 2020 by the authors. Licensee MDPI, Basel, Switzerland. This article is an open access article distributed under the terms and conditions of the Creative Commons Attribution (CC BY) license (http://creativecommons.org/licenses/by/4.0/). 